CLINICAL STUDY

\title{
Androgen receptor CAG repeat length polymorphism modifies the impact of testosterone on insulin sensitivity in men
}

\author{
Matthias Möhlig ${ }^{1,2}$, Ayman M Arafat ${ }^{1,2}$, Martin A Osterhoff ${ }^{2}$, Frank Isken ${ }^{1,2}$, Martin O Weickert ${ }^{1,3,4}$, \\ Joachim Spranger ${ }^{1,2}$, Andreas F H Pfeiffer ${ }^{1,2}$ and Christof Schöfl ${ }^{5}$ \\ ${ }^{1}$ Department of Endocrinology, Diabetes and Nutrition, Charité-University Medicine Berlin, Campus Benjamin Franklin, Hindenburgdamm 30,12200 \\ Berlin, Germany, ${ }^{2}$ Department of Clinical Nutrition, German Institute of Human Nutrition Potsdam-Rehbruecke, 14558 Nuthetal, Germany, \\ ${ }^{3}$ Warwickshire Institute for the Study of Diabetes, Endocrinology and Metabolism, University Hospitals Coventry and Warwickshire, Coventry, UK, \\ ${ }^{4}$ Clinical Sciences Research Institute, Warwick Medical School, University of Warwick, Coventry, UK and ${ }^{5}$ Division of Endocrinology and Diabetes, \\ Department of Medicine 1, University Hospital Erlangen, Friedrich-Alexander-University Erlangen-Nuremberg, Erlangen, Germany \\ (Correspondence should be addressed to M Möhlig; Email: matthias.moehlig@charite.de)
}

\begin{abstract}
Objective: Low circulating testosterone concentrations have been associated with insulin resistance (IR). Androgen action is mediated by the androgen receptor (AR) whose activity is modulated by a polymorphic CAG repeat sequence within exon 1. An interaction between testosterone and CAG repeat length (CAG length) with respect to IR has been described in women.

Objective: We investigated such a putative interaction between testosterone and the CAG length with respect to IR in men with normal glucose tolerance.

Design: Cross-sectional study.

Methods: In 113 non-diabetic men calculated free testosterone, the CAG length, and a multiplicative interaction term were investigated by multiple linear regression analysis for an association with IR, as indicated by homeostasis model assessment (HOMA \%S).

Results: In a multivariate regression analysis adjusted for age and body mass index, free testosterone, CAG length, and a multiplicative interaction term were significantly associated with IR $(P=0.001$, $P=0.001, P=0.01$ respectively). The model explained $36.6 \%$ of the variation of IR and predicted that in carriers with a CAG length of 23 , changes in testosterone would only minimally affect IR. For CAG lengths longer than 23, however, an increase in testosterone would improve IR, namely the longer the CAG length, the greater the effect. In contrast, in the case of CAG lengths shorter than 23, the effect of increasing testosterone would be the opposite.

Conclusions: In men, testosterone and the AR CAG repeat length polymorphism interacted with respect to IR. The interpretation of the association between testosterone and IR seems to require consideration of the AR CAG repeat polymorphism.
\end{abstract}

European Journal of Endocrinology 164 1013-1018

\section{Introduction}

In men lower testosterone levels have been associated with obesity, metabolic syndrome and type 2 diabetes mellitus (T2DM) (1-5). Insulin resistance (IR) linked to visceral adiposity (6) is regarded as a major pathophysiological mechanism leading to the metabolic syndrome and T2DM (7). It is well established that testosterone modulates body composition, with a higher visceral fat mass and lower fat-free mass in hypogonadal men (8), which can be reversed by testosterone replacement therapy $(9,10)$. Consistently, androgen ablation in patients with prostate cancer increases fat mass (11), IR (12), and the risk of T2DM (13). Several studies suggest a regulatory role of testosterone for metabolic processes like insulin sensitivity and associated pathologies such as the metabolic syndrome and T2DM, although intervention trials addressing the impact of testosterone on metabolism in men with low testosterone revealed inconsistent results $(9,10$, 14-16).

Most effects of testosterone are mediated at the molecular level through activation of the androgen receptor (AR), although some effects are mediated via the estrogen receptor after aromatization of testosterone. A CAG repeat polymorphism within the AR gene was found to influence the transactivation of androgendependent genes $(17,18)$. The length of the CAG repeats varies between $\sim 12$ and 30 repeats with an average length of 22 in Caucasian populations (19-21). An inverse relationship exists between AR CAG repeat length and the transcriptional activity of testosterone target genes (18). Associations between CAG repeats and components of the metabolic syndrome in men have been reported by some more recent studies. Data, however, regarding the association between the CAG 
polymorphism and the metabolic syndrome are conflicting $(22,23)$.

As testosterone action on target tissues is influenced by both the CAG repeat polymorphism and the circulating and local tissue androgen concentrations, we tested in this study the hypothesis that an interaction between circulating testosterone and the CAG repeat length polymorphism exists and that this interaction has an impact on insulin sensitivity in men.

In women suffering from hyperandrogenism, such an interaction between the CAG repeat length in the AR and testosterone with respect to IR has been described (24).

\section{Subjects and methods}

\section{Subjects}

The Metabolic Syndrome Berlin Potsdam (MeSyBePo) study $(25,26)$ is an ongoing study evaluating metabolic parameters in volunteers from the Berlin-Potsdam region in Germany, which has been started in 2002. The study has been approved by the local ethics committee and all participants gave written informed consent. The study has not been pre-registered. Anthropometry was performed by trained staff, and in case of unknown diabetes, glucose metabolism was defined by an oral glucose tolerance test. Medical history, smoking status, sporting activity, and dietary habits were assessed by questionnaires. Complete data and materials were available from 333 men at the time of the present investigation. The analysis was restricted to 113 men who were non-diabetic (27) and did not take any regular medication to avoid erroneous IR calculations in diabetic patients or medication bias.

\section{Assays}

Total testosterone was measured by an enzyme immunoassay (Adaltis, Freiburg, Germany). sexual hormone binding globulin (SHBG) and estradiol $\left(\mathrm{E}_{2}\right)$ were measured by fluoroimmunoassays (Wallac Delfia, Perkin Elmer, Rodgau-Jügesheim, Germany). Free testosterone was calculated from total testosterone and SHBG as published (28), using a web-based calculator (http:// www.issam.ch/freetesto.htm). Insulin was quantified by an ELISA (Mercodia, Uppsala, Sweden). All further biochemical and endocrine parameters were measured as described previously $(26,29)$.

The AR CAG repeat length polymorphism was measured by BioGlobe company (Hamburg, Germany). PCR products that were amplified by PCR using fluorescent-labeled forward primer 6FAM- $5^{\prime}$-TCCAGAATCTGTTCCAGAGCGTGC- $3^{\prime}$ and reverse primer $5^{\prime}$-CCCATTTCGCTTTTGACACA-' (Metabion International, Martinsried, Germany) were diluted with MegaBACE ET550-R size standard following manufacturer's recommendations and were subjected to capillary electrophoresis on MegaBACE 1000 DNA Analyzer. Data were analyzed with GE Healthcare's MegaBACE Fragment Profiler 1.2 Software (GE Healthcare, Piscataway, NJ, USA).

\section{Calculations and statistics}

IR was quantified by calculating HOMA $\%$ S from fasting glucose and insulin values using a computer program provided by Dr Levy (30). Body mass index (BMI) was calculated as body weight $(\mathrm{kg})$ divided by body height squared $\left(\mathrm{m}^{2}\right)$.

Statistical analyses were performed using SPSS Software (version 14.0, SPSS, Inc., Chicago, IL, USA). Significance was considered as two-tailed $\alpha<0.05$. To describe continuous variables, mean values and s.E.M. are presented. Correlation analysis was performed using the Spearman correlation coefficient. Different variables were compared for association with HOMA \%S by backward linear regression analysis. The relation between In testosterone, In AR CAG length, and IR was modeled by multiple linear regression analysis adjusted for ln BMI and ln age with In HOMA \%S as the dependent variable.

\section{Results}

The clinical and endocrine characteristics of the cohort are depicted in Table 1. The mean CAG length of the AR was $22.0 \pm 0.3$ ranging from 17 to 32 as shown in Fig. 1, which is similar to the results from previous Caucasian cohorts (20).

Table 1 Clinical and endocrine features of the study cohort $(n=113)$. Continuous variables are given as mean \pm S.E.M. and frequencies as $n(\%)$.

\begin{tabular}{|c|c|}
\hline Characteristics & Values \\
\hline Age (years) & $46.7 \pm 1.3$ \\
\hline BMI $\left(\mathrm{kg} / \mathrm{m}^{2}\right)$ & $27.8 \pm 0.6$ \\
\hline WHR & $0.95 \pm 0.01$ \\
\hline Waist circumference $(\mathrm{cm})$ & $97.0 \pm 1.4$ \\
\hline Total testosterone $(\mathrm{ng} / \mathrm{ml})$ & $4.84 \pm 0.18$ \\
\hline SHBG $(\mathrm{nmol} / \mathrm{l})$ & $41.5 \pm 1.75$ \\
\hline Calculated free testosterone $(\mathrm{ng} / \mathrm{ml})$ & $0.094 \pm 0.004$ \\
\hline AR CAG length & $22.0 \pm 0.3$ \\
\hline Estradiol $(\mathrm{pg} / \mathrm{ml})$ & $31.7 \pm 0.8$ \\
\hline Fasting glucose (mg/dl) & $90.3 \pm 0.7$ \\
\hline Fasting insulin (mU/l) & $8.2 \pm 0.5$ \\
\hline HOMA \%S & $118.2+9.3$ \\
\hline $\mathrm{HbA1c}(\%)$ & $5.3 \pm 0.04$ \\
\hline Total cholesterol $(\mathrm{mmol} / \mathrm{l})$ & $5.29 \pm 0.10$ \\
\hline HDL cholesterol (mmol/l) & $1.26 \pm 0.03$ \\
\hline LDL cholesterol (mmol/l/) & $3.27 \pm 0.09$ \\
\hline Triglycerides (mmol/l) & $1.59 \pm 0.10$ \\
\hline RRsys (mmHg) & $126 \pm 1.4$ \\
\hline RRdia (mmHg) & $78 \pm 0.9$ \\
\hline Overweight/obese subjects (BMI > $25 \mathrm{~kg} / \mathrm{m}^{2}$ ) & $74(65.5 \%)$ \\
\hline Smoker & $17(15.0 \%)$ \\
\hline
\end{tabular}




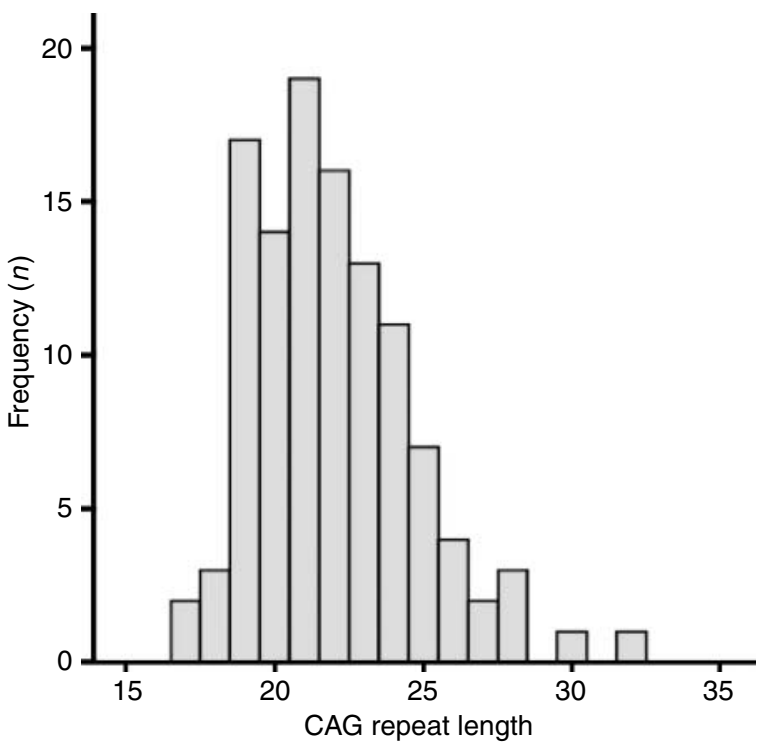

Figure 1 The distribution of the AR CAG repeat length polymorphism in the study cohort.

There was a significant correlation between both total testosterone and sexual hormone binding protein (SHBG) with HOMA \%S $(r=0.193, P=0.004$, and $r=0.483, P<0.001$ respectively). Backward regression analysis was performed to analyze the association between total testosterone, SHBG, age, and BMI with HOMA \%S. The final model consisted of SHBG $(\beta=1.51, P=0.002)$ and BMI $(\beta=-3.46, P=0.015)$, indicating that these two variables are the ones most strongly associated with IR. Calculated free testosterone, ranging from 0.03 to $0.32 \mathrm{ng} / \mathrm{ml}$, did neither correlate with HOMA $\% \mathrm{~S}(P=0.12)$ nor with the AR CAG repeat length $(P=0.33) . E_{2}$, a testosterone metabolite that is produced through aromatization, correlated with total testosterone $(r=0.19, P=0.045)$ while there was no correlation with SHBG $(P=0.13)$, calculated free testosterone $(P=0.45)$ or with HOMA $\% \mathrm{~S}(P=0.87)$.

Correlation analysis does not consider a putative interaction between two variables with respect to a third dependent parameter. Therefore, we performed multiple linear regression analysis including a multiplicative interaction term to address a potential interaction between free testosterone and the AR CAG repeat length polymorphism with respect to HOMA \%S. The model was calculated with $\ln$ transformed variables to yield normally distributed residuals as indicated by the Kolmogorov-Smirnov test $(P=0.20)$. Adjusted for $\ln$ age and $\ln$ BMI ln free testosterone $(P=0.001)$, the $\ln$ CAG repeat length $(P=0.001)$ and the multiplicative interaction term $(P=0.001)$ were significantly associated with In HOMA \%S (Table 2a). Ln free testosterone was negatively associated with In HOMA \%S, In CAG repeat length and the interaction term were inversely associated. According to the adjusted $r^{2}$ value, the entire model explained $36.6 \%$ of the variance of $\ln$ HOMA \%S. Therefore, this model was superior compared with a model only including ln age and In BMI, which explained $28.5 \%$ of the variance of $\ln$ HOMA \%S (Table 2b).

To illustrate the impact of the interaction, we used the model to calculate HOMA \%S values for different CAG repeat lengths and free testosterone concentrations for a 60 -year-old man with a BMI of $30 \mathrm{~kg} / \mathrm{m}^{2}$ as shown in Table 3. At a CAG repeat length of 23, changes in free testosterone had minimal impact on IR according to the model. At CAG lengths longer than 23, a rise in free testosterone was associated with an improvement of insulin sensitivity. This effect increased with longer CAG lengths. On the other hand, at CAG lengths shorter than 23, increasing concentrations of free testosterone worsened IR. Otherwise, at a given free testosterone in the low normal range $(0.075 \mathrm{ng} / \mathrm{ml})$, the impact of the CAG length on HOMA $\% \mathrm{~S}$ was minimal. With increasing or decreasing testosterone concentrations the impact of the CAG repeat length with respect to HOMA $\% S$ increased. In the case of increasing free testosterone concentrations, longer CAG repeat lengths were associated with improved insulin sensitivity. In contrast, insulin sensitivity was reduced in the case of decreasing free testosterone concentrations. Together, this demonstrates that the potential impact of testosterone on IR was modified by the $A R$ gene polymorphism.

\section{Discussion}

IR plays a central role in the pathophysiology of adiposity-related metabolic alterations, such as the metabolic syndrome and T2DM, and it is a well-accepted risk factor for coronary artery disease and cardiovascular events (for review, see (31)).

Several studies in men reported an association between low concentrations of testosterone and obesity, the metabolic syndrome, and T2DM (1-5). Furthermore, low testosterone appears to be an independent risk factor for the development of the metabolic syndrome (5) and T2DM (32). Consistent with a causal relationship, androgen deprivation has adverse effects on body composition with an increase in fat mass (11).

Table 2 Multivariate regression models with In HOMA \%S as the dependent variable. Model A was used to calculate Table 3.

\begin{tabular}{lcc}
\hline & Standardized $\boldsymbol{\beta}$ & $\boldsymbol{P}$ value \\
\hline Model A (adj. $\left.\mathrm{r}^{2}=0.366\right)$ & & \\
In BMI (kg/m $\left.\mathrm{m}^{2}\right)$ & -0.533 & $<0.001$ \\
In age (years) & -0.011 & $\mathrm{NS}$ \\
In free testosterone $(\mathrm{ng} / \mathrm{ml})$ & -7.362 & 0.001 \\
In CAG repeat length & 1.628 & 0.001 \\
In free testosterone $\times$ In CAG length & 7.060 & 0.001 \\
Model B (adj. $\left.r^{2}=0.285\right)$ & & \\
In BMl (kg/m $\mathrm{m}^{2}$ ) & -0.546 & $<0.001$ \\
In age (years) & 0.078 & $\mathrm{NS}$ \\
\hline
\end{tabular}


Table 3 HOMA \%S depending on free testosterone (f-testo) and the androgen receptor CAG repeat length for a 60 -year-old man with a body mass index of $30 \mathrm{~kg} / \mathrm{m}^{2}$ as predicted from a regression model (see Table 2 model A).

\begin{tabular}{lrrrrrrr}
\hline & \multicolumn{7}{c}{ CAG repeat length } \\
\cline { 2 - 8 } F-testo $(\mathrm{ng} / \mathrm{ml})$ & 20 & 21 & 22 & 23 & 24 & 25 & 26 \\
\hline 0.050 & 98 & 93 & 88 & 84 & 79 & 76 & 72 \\
0.075 & 81 & 81 & 82 & 82 & 82 & 83 & 83 \\
0.100 & 70 & 74 & 77 & 81 & 84 & 88 & 91 \\
0.200 & 50 & 58 & 68 & 78 & 89 & 102 & 116 \\
0.300 & 41 & 51 & 63 & 76 & 93 & 111 & 133 \\
0.400 & 36 & 46 & 59 & 75 & 95 & 118 & 146 \\
\hline
\end{tabular}

Furthermore, testosterone replacement in men with classical hypogonadism improves IR and metabolic parameters presumably through a positive effect on body composition with increasing lean body mass while reducing fat mass (9).

The AR is mediating the effects of testosterone at the molecular level. In vitro, the ability of the receptor to enhance transcription of testosterone-regulated genes has been shown to depend on a highly polymorphic CAG repeat microsatellite in exon 1 (18). It is generally assumed that there is a negative linear association between AR sensitivity and the CAG repeat length, which, however, has been questioned recently (33). In men, this polymorphism has been associated with the prognosis of prostate cancer (34); with obesity (35) and body composition (22); and with metabolic parameters such as high-density lipoprotein cholesterol (36), fasting glucose, or the risk of metabolic syndrome (23). Consistently, in women suffering from hyperandrogenism, the CAG repeat length in the AR modifies the relation between testosterone and IR (24). Therefore, it appears reasonable to consider the CAG length polymorphism when investigating the relationship between testosterone and IR in men.

In this study, we present novel data concerning the interaction between free testosterone concentration and the AR CAG repeat length polymorphism with respect to IR in men. We describe that at short CAG lengths, increasing concentrations of free testosterone appeared to worsen insulin sensitivity, as derived from multiple linear regression analysis including a multiplicative interaction term between free testosterone and the CAG repeat length. The effect attenuated with rising CAG length until it turns into the opposite effect at a CAG length longer than 23. Vice versa, at free testosterone concentrations within the reference range, the modifying impact of the CAG repeat length polymorphism appeared to be minimal, whereas in men with mild-to-moderate low testosterone levels as in late-onset hypogonadism, the CAG repeat length might well modulate the metabolic effects of testosterone.

IR is a multifactorial parameter that is determined by a number of metabolic factors and processes involving several tissues like fat, muscle, and liver (37).
It appears likely that testosterone-dependent mechanisms modulate more than one pathway controlling IR. Our model, which fits best the clinical parameters measured in our cohort, describes a complex interaction between testosterone concentration and CAG repeat polymorphism with respect to IR. This is consistent with the assumption of the involvement of several differentially regulated androgen-dependent pathways modulating IR. The molecular pathways involved, however, remain to be defined. Our model, although it indicates a more complex interaction, does not necessarily argue against a linear inverse relationship between AR CAG repeat length and, for e.g. the transcriptional activity of individual testosterone target genes (18). A similar interaction between testosterone and AR CAG repeat length with respect to IR has been seen in hyperandrogenic women (24) suggesting that the underlying mechanisms could be operational in both genders.

The mean CAG length in our cohort was similar to that reported from other Caucasian cohorts (20). In contrast to several previous reports $(20,35,38,39)$, there was no correlation between the CAG length polymorphism and total or free testosterone, which, however, is in line with another recent publication (40). In our cohort, insulin sensitivity ranged from very sensitive to highly resistant. IR was calculated as HOMA $\%$, a widely used and accepted measure of IR in population studies (41). HOMA \%S has been shown to correlate with euglycemic clamp data in cohorts of similar size (41). Total testosterone and SHBG correlated with IR. In a backward regression analysis, however, only SHBG and BMI were significantly associated with HOMA \%S, indicating that the association with total testosterone might depend on SHBG. This interpretation is consistent with the lack of an association between free testosterone and IR. The finding that SHBG showed an impact on IR independent of BMI fits well with recent reports demonstrating an association between SHBG levels and diabetes risk (42).

Several androgen effects like those on bone metabolism are mediated through $\mathrm{E}_{2}$, a metabolite of testosterone formed upon peripheral aromatization, e.g. in adipose tissue (43). As expected, $\mathrm{E}_{2}$ correlated with total testosterone, although there was no correlation with SHBG, free testosterone, or with HOMA \%S.

Consistent with a recent report from the European Aging Male Study (20), there was no association between the AR CAG repeat length and IR as determined by HOMA \%S. This contrasts to previous studies reporting a correlation with fasting insulin (22) or an association with the risk for suffering from the metabolic syndrome (23). Remarkably, the directions of the association between the CAG length polymorphism and the metabolic parameters were contradictory in these two studies $(22,23)$.

Limitations of this study are mentioned, which include the relatively small size of the investigated cohort, although within the range of others exploring 
the association of the AR CAG repeat length polymorphism on components of the metabolic syndrome $(22,23)$. Furthermore, we reproduced our results obtained in women suffering from hyperandrogenism (24), which support the relevance of the present findings. As the model has been calculated from clinical data, the predicted IR values toward or above the boundary values for testosterone and CAG repeat lengths of the cohort are expected to become less accurate. Therefore, confirmation of the results in larger independent cohorts and in particular in intervention trials considering CAG repeat length is desirable. The design of this study does not allow commenting on the direction of the observed association. The observation, however, of an interaction with a genetically determined and hence invariable polymorphism supports the view that testosterone in men is affecting IR rather than vice versa.

In conclusion, the AR CAG repeat polymorphism was found to modify the impact of testosterone on IR in men. The interaction observed in this study might contribute to the conflicting metabolic results reported from intervention trials in late-onset hypogonadism $(9,10$, 14-16). According to our analysis, the CAG repeat length needs to be considered if the relationship between testosterone and IR is addressed.

\section{Declaration of interest}

The authors declare that there is no conflict of interest that could be perceived as prejudicing the impartiality of the research reported.

\section{Funding}

The study was supported by an unrestricted grant from Bayer Vital, Germany.

\section{Acknowledgments}

The authors thank B Faust and K Sprengel for their excellent technical assistance.

\section{References}

1 Barrett-Connor E. Lower endogenous androgen levels and dyslipidemia in men with non-insulin-dependent diabetes mellitus. Annals of Internal Medicine 1992117 807-811.

2 Svartberg J, von Muhlen D, Sundsfjord J \& Jorde R. Waist circumference and testosterone levels in community dwelling men. The Tromso study. European Journal of Epidemiology 200419 657-663. (doi:10.1023/B:EJEP.0000036809.30558.8f)

3 Haring R, Völzke H, Felix SB, Schipf S, Dörr M, Rosskopf D, Nauck M, Schöfl C \& Wallaschofski H. Prediction of metabolic syndrome by low serum testosterone levels in men: results from the study of health in Pomerania. Diabetes 200958 2027-2031. (doi:10.2337/db09-0031)

4 Yeap BB, Chubb SA, Hyde Z, Jamrozik K, Hankey GJ, Flicker L \& Norman PE. Lower serum testosterone is independently associated with insulin resistance in non-diabetic older men: the Health in Men Study. European Journal of Endocrinology 2009161 591-598. (doi:10.1530/EJE-09-0348)
5 Li C, Ford ES, Li B, Giles WH \& Liu S. Association of testosterone and sex hormone-binding globulin with metabolic syndrome and insulin resistance in men. Diabetes Care 201033 1618-1624. (doi:10.2337/dc09-1788)

6 Racette SB, Evans EM, Weiss EP, Hagberg JM \& Holloszy JO. Abdominal adiposity is a stronger predictor of insulin resistance than fitness among 50-95 year olds. Diabetes Care 200629 673-678. (doi:10.2337/diacare.29.03.06.dc05-1605)

7 Haffner SM, Valdez RA, Hazuda HP, Mitchell BD, Morales PA \& Stern MP. Prospective analysis of the insulin-resistance syndrome (syndrome X). Diabetes 199241 715-722. (doi:10.2337/diabetes. 41.6.715)

8 Dhindsa S, Bhatia V, Dhindsa G, Chaudhuri A, Gollapudi GM \& Dandona P. The effects of hypogonadism on body composition and bone mineral density in type 2 diabetic patients. Diabetes Care 200730 1860-1861. (doi:10.2337/dc07-0337)

9 Kapoor D, Goodwin E, Channer KS \& Jones TH. Testosterone replacement therapy improves insulin resistance, glycaemic control, visceral adiposity and hypercholesterolaemia in hypogonadal men with type 2 diabetes. European Journal of Endocrinology 2006154 899-906. (doi:10.1530/eje.1.02166)

10 Nair KS, Rizza RA, O'Brien P, Dhatariya K, Short KR, Nehra A, Vittone JL, Klee GG, Basu A, Basu R, Cobelli C, Toffolo G, Dalla Man C, Tindall DJ, Melton LJ III, Smith GE, Khosla S \& Jensen MD. DHEA in elderly women and DHEA or testosterone in elderly men. New England Journal of Medicine 2006355 1647-1659. (doi:10. 1056/NEJMoa054629)

11 Nowicki M, Bryc W \& Kokot F. Hormonal regulation of appetite and body mass in patients with advanced prostate cancer treated with combined androgen blockade. Journal of Endocrinological Investigation 200124 31-36.

12 Smith MR, Lee H \& Nathan DM. Insulin sensitivity during combined androgen blockade for prostate cancer. Journal of Clinical Endocrinology and Metabolism 200691 1305-1308. (doi:10. 1210/jc.2005-2507)

13 Keating NL, O'Malley AJ, Freedland SJ \& Smith MR. Diabetes and cardiovascular disease during androgen deprivation therapy: observational study of veterans with prostate cancer. Journal of National Cancer Institute 2010102 39-46. (doi:10.1093/jnci/ djp404)

14 Saad F, Gooren L, Haider A \& Yassin A. Effects of testosterone gel followed by parenteral testosterone undecanoate on sexual dysfunction and on features of the metabolic syndrome. Andrologia 200840 44-48. (doi:10.1111/j.1439-0272.2008.00807.x)

15 Emmelot-Vonk MH, Verhaar HJ, Nakhai Pour HR, Aleman A, Lock TM, Bosch JL, Grobbee DE \& van der Schouw YT. Effect of testosterone supplementation on functional mobility, cognition, and other parameters in older men: a randomized controlled trial. Journal of the American Medical Association 2008299 39-52. (doi:10.1001/jama.2007.51)

16 Basaria S, Coviello AD, Travison TG, Storer TW, Farwell WR, Jette AM, Eder R, Tennstedt S, Ulloor J, Zhang A, Choong K, Lakshman KM, Mazer NA, Miciek R, Krasnoff J, Elmi A, Knapp PE, Brooks B, Appleman E, Aggarwal S, Bhasin G, Hede-Brierley L, Bhatia A, Collins L, LeBrasseur N, Fiore LD \& Bhasin S. Adverse events associated with testosterone administration. New England Journal of Medicine 2010363 109-122. (doi:10.1056/ NEJMoa1000485)

17 Chamberlain NL, Driver ED \& Miesfeld RL. The length and location of CAG trinucleotide repeats in the androgen receptor N-terminal domain affect transactivation function. Nucleic Acids Research 199422 3181-3186. (doi:10.1093/nar/22.15.3181)

18 Beilin J, Ball EM, Favaloro JM \& Zajac JD. Effect of the androgen receptor CAG repeat polymorphism on transcriptional activity: specificity in prostate and non-prostate cell lines. Journal of Molecular Endocrinology 200025 85-96. (doi:10.1677/jme.0. 0250085)

19 Zitzmann M \& Nieschlag E. Androgen receptor gene CAG repeat length and body mass index modulate the safety of long-term 
intramuscular testosterone undecanoate therapy in hypogonadal men. Journal of Clinical Endocrinology and Metabolism 200792 3844-3853. (doi:10.1210/jc.2007-0620)

20 Huhtaniemi IT, Pye SR, Limer KL, Thomson W, O'Neill TW, Platt H, Payne D, John SL, Jiang M, Boonen S, Borghs H, Vanderschueren D, Adams JE, Ward KA, Bartfai G, Casanueva F, Finn JD, Forti G, Giwercman A, Han TS, Kula K, Lean ME, Pendleton N, Punab M, Silman AJ \& Wu FC. Increased estrogen rather than decreased androgen action is associated with longer androgen receptor CAG repeats. Journal of Clinical Endocrinology and Metabolism 200994 277-284. (doi:10.1210/jc.2008-0848)

21 Vermeersch H, T'Sjoen G, Kaufman JM, Vincke J \& Van Houtte M. Testosterone, androgen receptor gene CAG repeat length, mood and behaviour in adolescent males. European Journal of Endocrinology 2010163 319-328. (doi:10.1530/EJE-10-0090)

22 Zitzmann M, Gromoll J, von Eckardstein A \& Nieschlag E. The CAG repeat polymorphism in the androgen receptor gene modulates body fat mass and serum concentrations of leptin and insulin in men. Diabetologia 200346 31-39. (doi:10.1007/s00125-0020980-9)

23 Skjaerpe PA, Giwercman YL, Giwercman A \& Svartberg J. Androgen receptor gene polymorphism and the metabolic syndrome in 60-80 years old Norwegian men. International Journal of Andrology 201033 500-506. (doi:10.1111/j.13652605.2008.00942.x)

24 Möhlig M, Jürgens A, Spranger J, Hoffmann K, Weickert MO, Schlösser HW, Schill T, Brabant G, Schüring A, Pfeiffer AF, Gromoll J \& Schöfl C. The androgen receptor CAG repeat modifies the impact of testosterone on insulin resistance in women with polycystic ovary syndrome. European Journal of Endocrinology 2006 155 127-130. (doi:10.1530/eje.1.02195)

25 Schulze MB, Hoffmann K, Boeing H, Linseisen J, Rohrmann S, Möhlig M, Pfeiffer AF, Spranger J, Thamer C, Häring HU, Fritsche A \& Joost HG. An accurate risk score based on anthropometric, dietary, and lifestyle factors to predict the development of type 2 diabetes. Diabetes Care 200730 510-515. (doi:10.2337/dc06-2089)

26 Ruhla S, Weickert MO, Arafat AM, Osterhoff M, Isken F, Spranger J, Schöfl C, Pfeiffer AF \& Möhlig M. A high normal TSH is associated with the metabolic syndrome. Clinical Endocrinology 201072 696-701. (doi:10.1111/j.1365-2265.2009.03698.x)

27 Definition, Diagnosis and Classification of Diabetes Mellitus and its Complications. In: Report of a WHO Consultation, Part 1. WHO, 1999.

28 Vermeulen A, Verdonck L \& Kaufman JM. A critical evaluation of simple methods for the estimation of free testosterone in serum. Journal of Clinical Endocrinology and Metabolism $1999 \mathbf{8 4}$ 3666-3672. (doi:10.1210/jc.84.10.3666)

29 Möhlig M, Spranger J, Osterhoff M, Ristow M, Pfeiffer AF, Schill T, Schlösser HW, Brabant G \& Schöfl C. The polycystic ovary syndrome per se is not associated with increased chronic inflammation. European Journal of Endocrinology $2004 \mathbf{1 5 0}$ 525-532. (doi:10.1530/eje.0.1500525)

30 Levy JC, Matthews DR \& Hermans MP. Correct homeostasis model assessment (HOMA) evaluation uses the computer program. Diabetes Care 199821 2191-2192. (doi:10.2337/diacare.21.12.2191)

31 Kahn R, Buse J, Ferrannini E \& Stern M. The metabolic syndrome: time for a critical appraisal. Joint statement from the American Diabetes Association and the European Association for the Study of Diabetes. Diabetologia $2005 \mathbf{4 8}$ 1684-1699. (doi:10.1007/ s00125-005-1876-2)
32 Vikan T, Schirmer H, Njolstad I \& Svartberg J. Low testosterone and sex hormone-binding globulin levels and high estradiol levels are independent predictors of type 2 diabetes in men. European Journal of Endocrinology 2010162 747-754. (doi:10.1530/EJE09-0943)

33 Nenonen H, Bjork C, Skjaerpe PA, Giwercman A, Rylander L, Svartberg J \& Giwercman YL. CAG repeat number is not inversely associated with androgen receptor activity in vitro. Molecular Human Reproduction 201016 153-157. (doi:10.1093/molehr/ gap097)

34 Shimbo M, Suzuki H, Kamiya N, Imamoto T, Komiya A, Ueda T, Watanabe M, Shiraishi T \& Ichikawa T. CAG polymorphic repeat length in androgen receptor gene combined with pretreatment serum testosterone level as prognostic factor in patients with metastatic prostate cancer. European Urology 2005 47 557-563. (doi:10.1016/j.eururo.2004.10.016)

35 Stanworth RD, Kapoor D, Channer KS \& Jones TH. Androgen receptor CAG repeat polymorphism is associated with serum testosterone levels, obesity and serum leptin in men with type 2 diabetes. European Journal of Endocrinology 2008159 739-746. (doi:10.1530/EJE-08-0266)

36 Zitzmann M, Brune M, Kornmann B, Gromoll J, von Eckardstein S, von Eckardstein A \& Nieschlag E. The CAG repeat polymorphism in the AR gene affects high density lipoprotein cholesterol and arterial vasoreactivity. Journal of Clinical Endocrinology and Metabolism 200186 4867-4873. (doi:10.1210/jc.86.10.4867)

37 Despres JP \& Lemieux I. Abdominal obesity and metabolic syndrome. Nature 2006444 881-887. (doi:10.1038/nature05488)

38 Travison TG, Shackelton R, Araujo AB, Morley JE, Williams RE, Clark RV \& McKinlay JB. Frailty, serum androgens, and the CAG repeat polymorphism: results from the Massachusetts Male Aging Study. Journal of Clinical Endocrinology and Metabolism 201095 2746-2754. (doi:10.1210/jc.2009-0919)

39 Kristal AR, Price DK, Till C, Schenk JM, Neuhouser ML, Ockers S, Lin DW, Thompson IM \& Figg WD. Androgen receptor CAG repeat length is not associated with the risk of incident symptomatic benign prostatic hyperplasia: results from the Prostate Cancer Prevention Trial. Prostate 201070 584-590. (doi:10.1002/pros. 21092)

40 Guadalupe-Grau A, Rodriguez-Gonzalez FG, Ponce-Gonzalez JG, Dorado C, Olmedillas H, Fuentes T, Perez-Gomez J, SanchisMoysi J, Diaz-Chico BN \& Calbet JA. Bone mass and the CAG and GGN androgen receptor polymorphisms in young men. PLoS ONE 20105 e11529. (doi:10.1371/journal.pone.0011529)

41 Wallace TM, Levy JC \& Matthews DR. Use and abuse of HOMA modeling. Diabetes Care 200427 1487-1495. (doi:10.2337/ diacare.27.6.1487)

42 Ding EL, Song Y, Manson JE, Hunter DJ, Lee CC, Rifai N, Buring JE, Gaziano JM \& Liu S. Sex hormone-binding globulin and risk of type 2 diabetes in women and men. New England Journal of Medicine 2009361 1152-1163. (doi:10.1056/NEJMoa0804381)

43 Spratt DI, Morton JR, Kramer RS, Mayo SW, Longcope C \& Vary CP. Increases in serum estrogen levels during major illness are caused by increased peripheral aromatization. American Journal of Physiology, Endocrinology and Metabolism 2006291 E631-E638. (doi:10.1152/ajpendo.00467.2005)

Received 22 March 2011

Accepted 28 March 2011 